\title{
Perfil socioprofissional do professor de EAD (Ensino a Distância) em Natal (RN)
}

\author{
Socio-profesional profile of a professor of Distance Education (DE) in Natal (RN)
}

Alda Karoline Lima da Silva, Jorge Tarcísio da Rocha Falcão, Camila Costa Torres

Universidade Federal do Rio Grande do Norte, Natal, RN Brasil, e-mails: aldakarolinel@ yahoo.com.br; falcão.jorge@gmail. com; pcamilatorres@gmail.com

Recebido: 03/06/2012 Received: 06/03/2012

Aprovado: $18 / 11 / 2012$ Approved: 11/18/2012

\section{Resumo}

O objetivo do estudo foi realizar um mapeamento socioprofissional dos professores que atuam na Educação a Distância (EAD) em duas instituições de ensino superior da cidade de Natal (RN), com intuito de analisar o impacto que a entrada do professor na EAD produz em sua atuação docente. Foi realizado um mapeamento e análise documental. As análises estatísticas descritivas e inferenciais do mapeamento contemplaram uma amostra de 70 participantes, sendo 28 homens e 41 mulheres. 65,7\% dos participantes estavam vinculados à instituição pública e 30\% à instituição privada; 31,4\% tinham o grau de mestre, $28,6 \%$ eram doutores e $26,3 \%$ de especialistas. 54,3\% exerciam a função de tutor a distância, e 44,3\% eram professores regentes. Após análise descritiva multidimensional de clusterização, foi detectada a existência de dois grupos (tutor a distância e professor regente), e as variáveis mais importantes de distinção foram: função, titulação, renda, atividades desenvolvidas e forma de ingresso na EAD. A existência destes dois grupos permitiu demonstrar dois modelos de EAD distintos, tendo em vista concepções de ensino e o papel do professor. Nessa segmentação, percebe-se que alguns modelos de EAD tendem a centralizar a figura do docente como único ator, apontando-se também que o alargamento do leque de atividades não necessariamente está atrelado a uma concepção mais ampliada de educação, e que o domínio de competências técnicas amplia as competências pedagógicas. Pelo fato de a EAD ser recente, na era da tecnologia da informação, esse tipo de educação demanda das instituições um aperfeiçoamento de processos de ensino-aprendizagem, tendo em vista os aportes desse novo ambiente de trabalho.

Palavras-chave: EAD. Professor. Atividade profissional.

\section{Abstract}

This research aimed at describing the socio-professional profile of professors living in Natal (RN, Brazil) who have professional activities in the context of Distance Education (DE), in two local universities. We aimed also at verifying the effect of participating in DE activities on the traditional, usual professional activities of these professors. The research covered both documental and empirical analysis. Data analysis was based on questionnaires answered by 70 participants, 28 men and 41 women. 65,7\% of this group serve for public university, while 30\% at a private university. 31,4\% of participants have master's degree, 28,6\% got PhD and 26,3\% were specialists in their areas. $54,3 \%$ acted as distant learning tutors, and $44,3 \%$ were professors. A

Psicol. Argum. 2014 jul./set., 32(78), 117-125 


\begin{abstract}
multidimensional descriptive analysis (cluster analysis) allowed demonstrating the existence of two groups of professors, with different profiles (distant learning tutors and professors). Relevant variables for establishing this distinction were: function at the university, academic degree, level of income, professional activities and aspects of their participation in DE. The very existence of these two groups allowed the demonstration of two models of DE, taking into account learning conceptions and the professor's role. In fact, some DE models emphasize the professor's role, while others accept to share the learning tasks with students. In the context of new technologies in an informatized world DE, as a recent domain in Education, forces educational institutions and universities to improve their educational models.
\end{abstract}

Keywords: DE. Professor. Professional activities.

\section{Introdução}

Estudos apontam que entre as mudanças produzidas pela educação a distância (EAD), o papel que o professor é solicitado a desempenhar apresenta-se como uma questão complexa e polêmica (AbreuTardelli, 2006; Belloni, 2001; Peters, 2004, 2006; Sarmet \& Abrahão, 2007). Há uma diversificação nos termos usados para designar os professores, bem como um leque de atividades por eles desenvolvido na EAD. Como, geralmente, são profissionais oriundos da modalidade presencial, estão em processo de adaptação às mudanças produzidas pelas atividades e funções que lhes foram destinadas na EAD (Barreto, 2004; Torres, 2007).

Este estudo remete a uma pesquisa mais ampla que buscou analisar as interfaces que a atividade do professor na EAD, notadamente em duas instituições de ensino superior (IES) norte-rio-grandenses, estabeleceram em relação à atividade docente de modo geral, tendo em vista que os docentes frequentemente atuam em ambos os espaços de atividade laboral (presencial e a distância). Ressalta-se que a prática da educação a distância nas universidades participantes não ultrapassava nove anos de existência, portanto, a EAD no espaço regional ainda é muito recente.

Nesse sentido, uma das finalidades do estudo foi conhecer o perfil socioprofissional dos professores atuando na EAD nessas universidades, que na época eram as que tinham oferta de cursos a distância em caráter pleno pelo Ministério da Educação (MEC, 2010). Para a realização do mapeamento socioprofissional, foco de análise desse artigo, optou-se pelo recurso tradicional de pesquisa (questionário), por mostrar-se adequado para fornecer dados gerais de uma amostra profissional que, até então, não tinha sido contemplada com uma organização de dados estatísticos descritivos sistematizados.

A educação a distância é conceituada em diversos estudos (Belloni, 2001; Gonzalez, 2005; Litwin, 2001) como uma modalidade de educação mediada por um artefato tecnológico de comunicação remota (telemática), que abole o contexto interacional tradicional da presença física em sala de aula do professor e dos alunos para a concretização do processo ensino-aprendizagem. De tal processo resulta a reconfiguração dos papéis do professor e do aluno. A modalidade, segundo Litwin (2001), baseia-se na premissa que os processos de ensino-aprendizagem ocorrem em situações não convencionais, não sendo necessária a presença compartilhada em espaço e tempo pré-definidos, enfatizando-se a autonomia dos alunos em relação à escolha de espaços e tempos para o estudo.

Segundo Peters (2006), as mudanças que aconteceram nos sistemas de ensino foram provocadas por transformações decorrentes do cenário econômico-laboral. As Novas Tecnologias de Informação e Comunicação (NTICs) representaram os instrumentos de concretização de um cenário socioeconômico que precisava transcender as barreiras de lugar, tempo e circunstância, tornando-as flexíveis e adaptáveis e, no caso da educação, também podiam atender aos mais variados tipos de estudantes.

Uma das questões centrais discutidas na EAD é o papel que é destinado ao docente nesse cenário (Belloni, 2001; Abreu-Tardelli, 2006; Almeida, 2005; Oliveira, 2005). No ensino convencional, há uma perspectiva bastante disseminada pelo senso comum de que o processo de ensino-aprendizagem encontra-se centrado na modelagem de informações 
e comportamentos dos alunos, a partir da ação do professor. Em alguns modelos de EAD, assim como também nos modos presenciais de ensino, há uma centralização no papel do professor nos processos de ensino.

Uma das mudanças provocadas pela EAD é o deslocamento da centralidade do ensino do professor para a aprendizagem do aluno. Entra em cena a ideia de um aluno autônomo, afastado no tempo e no espaço, ou seja, fisicamente distante do professor e participante em atividade não síncrona em relação ao momento de geração da atividade pedagógica (Lapa \& Pretto, 2010).

Peters (2004) e Moraes (2003) sugerem que o papel assumido pelo docente na atividade de EAD representa uma mudança na cultura de ensino-aprendizagem, não sendo ele mais o centro de todas as informações, mas preponderantemente um guia, um facilitador. Essa ruptura com as concepções de ensino em que o professor apresenta-se como figura central é advinda das mudanças ocorridas na modalidade presencial, e agora assimiladas pela EAD. Para Belloni (2001) há uma reconfiguração no papel do professor, uma transformação do professor de uma entidade individual para uma entidade coletiva. Esta autora chama a atenção para a necessidade do professor, nesse novo contexto de trabalho, de abrir mão de certa centralidade magistral em termos de lugar social para seu desempenho docente, ampliando o espaço de iniciativas e participação dos alunos.

Comenta ainda que em virtude das mudanças tecnológicas da contemporaneidade, tanto os professores da EAD quanto os da educação presencial devem se apropriar das NTICs como estratégia de adaptação às exigências do cenário tecnológico-informacional (Alves \& Nova, 2002; Belloni, 2001). Configura-se dessa maneira uma EAD centrada em um sujeito coletivo e na formação de comunidades - virtuais ou presenciais - com o objetivo de preparar o professor para dominar diferentes formas de acesso às informações, de modo a (re)construir o cotidiano de sua prática como ator e autor da própria atividade.

Diante de tais considerações acerca das expectativas em relação ao perfil do docente contemporâneo que transita do ensino presencial tradicional para a EAD - e vice-versa - surge o interesse de verificar, empiricamente, qual grupo de trabalhadores está em foco, e quais são as características do perfil deles do ponto de vista sociodemográfico e atitudinal. A seção seguinte detalha os objetivos operacionais e caminhos de operacionalização seguidos para a obtenção das respostas a tais questões.

\section{Método}

A presente pesquisa buscou estabelecer com mais clareza aspectos caracterizadores do perfil sociodemográfico dos docentes envolvidos com EAD (Educação a Distância) em duas instituições de ensino superior (uma pública e outra privada) da cidade de Natal (RN). A etapa inicial da pesquisa envolveu visitas de aproximação com o campo de atividade profissional visado, para explicitação dos objetivos do estudo e compreensão das especificidades dos cenários institucionais que ofertavam a modalidade a distância.

O contato com o campo ocorreu de modo presencial e virtual, e envolveu os coordenadores acadêmicos/pedagógicos dos núcleos de educação a distância das Instituições de Ensino Superior (IES) participantes, seja para autorização inicial da pesquisa - atividades relacionadas a aspectos formais exigidos pelo comitê de ética ${ }^{1}$ - até encontros para reconhecimento e aproximação do cenário. Foram solicitados aos coordenadores os contatos de correio eletrônico dos professores, que receberam em seus e-mails um convite para participar da pesquisa.

Os procedimentos de campo foram desenvolvidos em duas etapas: 1) mapeamento socioprofissional dos professores que atuam em EAD em duas universidades norte-rio-grandense e 2) análise documental.

Antes do envio aos professores, o questionário socioprofissional foi respondido por dois futuros participantes, com intuito de verificar a compreensão das questões elaboradas. Atualmente, o quadro de docentes que atuam na EAD dessas universidades é de aproximadamente 100 professores, e tivemos a participação de 70 deles. Deste grupo de participantes, $65,7 \%$ são oriundos de instituição pública e $30 \%$ de instituição privada, os demais $4,3 \%$ são de instituições públicas e privadas.

1 O estudo foi aprovado pelo comitê de ética do hospital universitário Onofre Lopes (HUOL-UFRN), vinculado à UFRN, em seus aspectos éticos e metodológicos com o protocolo CEP/HOUL: 557/11 em 05 de julho de 2011.

Psicol. Argum. 2014 jul./set., 32(78), 117-125 
Ao longo de aproximadamente dois meses foi realizada a coleta virtual, através de respostas ao questionário disponibilizado via internet. Foram enviados três convites de participação para a pesquisa, com intervalo de três a quatro semanas entre um e outro. Ao final da coleta, ao se atingir o nível de participação acima aludido $(70 \%$ dos sujeitos do grupo de referência), foi encerrada a fase de coleta de questionários respondidos e enviada uma nota de agradecimento pela participação na pesquisa a todos os respondentes.

Os dados provenientes de análise documental e do questionário socioprofissional foram então registrados em um banco de dados de aplicativo informatizado e analisados através do uso de ferramentas estatísticas descritivas (uni e multidimensionais, notadamente análises de tipo cluster $^{2}$ ) e, quando necessário, recorreu-se ao uso de ferramentas inferenciais do tipo não paramétrico, para verificação de efeitos de variáveis e graus de diferenciação entre grupos.

\section{Resultados}

As análises de frequências simples das variáveis propostas no questionário mostraram que a amostra de participantes foi composta por 28 homens e 41 mulheres, e um deles não indicou o sexo. $\mathrm{Na}$ Tabela 1 seguem os principais dados de perfil dos participantes:

Cabe aqui considerar que a terminologia adotada para a designação do professor na EAD sofre certa variação, tendo-se portanto decidido, no contexto da presente pesquisa, adotar a denominação professor/docente. Contudo, compete esclarecer a nomenclatura usada nas duas IES em que a pesquisa foi desenvolvida.

2 As análises descritivas multidimensionais do tipo cluster (grupo, categoria) têm o objetivo de agrupar um conjunto de informações contidas em variáveis categoriais-descritivas de forma a obter uma visualização de grupos que seja interpretável pelo pesquisador. Um cluster diz respeito, portanto, a uma coleção de objetos informacionais (referentes a sujeitos, eventos etc) que têm pontos em comum, sendo, portanto, em alguma medida, similares uns aos outros, e dissimilares a objetos pertencentes a outros clusters ou grupos.
Nessas IES evidenciam-se configurações de EAD diferenciadas, notadamente no que diz respeito à prescrição da atividade docente, conforme apontou as análises documentais. Em uma das universidades, por exemplo, aponta-se a existência de três figuras que atuam na mediação do processo de ensino: professor regente, tutor presencial e tutor a distância.

Os dados resumidos pela tabela 2 referem-se ao tipo de atividades desenvolvidas na EAD pelos professores; pode-se mencionar que as atividades de tutoria são as que predominam, ver tabela 2 .

A Tabela 3 aponta dados referentes às especificidades do trabalho em EAD, como os aspectos relacionados à forma de ingresso na modalidade, especificidades do trabalho prescrito, como carga horária (EAD e presencial), percepção do trabalho real, locais que desenvolvem a atividade de trabalho, quantidade de alunos por professor em turma virtual, e renda. Seguem abaixo os detalhes.

Na Tabela 4, os dados apresentados referem-se à avaliação que o professor faz sobre o trabalho que desenvolve na EAD, o quanto considera importante e motivadora sua atividade pedagógica nessa modalidade, e os suportes que os docentes recebem para realização das atividades em EAD.

Após essa breve análise descritiva da caracterização dos professores que atuam em EAD, aponta-se a seguir a análise de cluster, que objetivou assinalar a diferenciação de possíveis grupos dentro da amostra principal dos participantes. Para formação de grupos distintos, as variáveis consideradas de maior força aparecem como as que melhor caracterizam o perfil de cada grupo. Após a clusterização, verificou-se a existência de dois grupos (Tabela 5), que foi denominado de Grupo T (de tutores) e Grupo $\mathrm{P}$ (de professores). As variáveis mais importantes de distinção dos grupos foram em ordem decrescente de valoração: 1) Função; 2) Titulação; 3) Renda; 4) Atividades desenvolvidas na EAD; 5) Forma de ingresso na EAD; 6) Instituição de vinculação.

Como foi observado, para cada um dos dois grupos, temos as variáveis que contribuíram significativamente (ou seja, com efeito de diferenciação com probabilidade de casualidade inferior ao limiar convencional de 5\%) para o processo de constituição deles, bem como as que não contribuíram, por apresentarem distribuições homogêneas entre os grupos. Nesse sentido, não podem ser usadas assim como fator de diferenciação de um grupo para o outro. 
Tabela 1 - Dados do perfil dos professores que atuam em EAD

\begin{tabular}{lc}
\hline Variável & Professores da EAD \\
\hline Faixa etária & Dos 26 a 35 anos: $37,1 \%$ \\
Estado civil & Dos 36 a 45 anos: $27,1 \%$ \\
\hline Instituição de vinculação & Casados $/$ união estável: $57,1 \%$ \\
& Instituição pública: $65,7 \%$ \\
Instituição privada: $30 \%$
\end{tabular}

Tabela 2 - Dados sobre as atividades desenvolvidas pelos professores que atuam em EAD

\begin{tabular}{lcc}
\hline Atividades desenvolvidas pelos professores da EAD & Realizam & Não realizam \\
\hline Tarefas de concepção e realização de curso & $57,1 \%$ \\
Planejamento e organização da distribuição dos materiais e da administração acadêmica & $84,3 \%$ \\
$\begin{array}{l}\text { Acompanhamento do estudante (tutoria) } \\
\begin{array}{l}\text { Demais atividades (elaboração de materiais didáticos, planejamento, reuniões administrativas, } \\
\text { entre outras) que podem exercer na EAD }\end{array}\end{array}$ & $78,6 \%$ \\
\hline
\end{tabular}

Tabela 3 - Especificidades da atividade de trabalho dos professores que atuam em EAD

\begin{tabular}{|c|c|}
\hline Variável & Professores da EAD \\
\hline Forma de ingresso na EAD & $\begin{array}{c}\text { Convite: } 44,3 \% \\
\text { Processo seletivo: } 30 \%\end{array}$ \\
\hline Tipos de curso nos quais esses professores atuam na EAD & Graduação: 98,6\% \\
\hline Carga horária institucional dedicada à EAD & $\begin{array}{l}\text { Entre } 4 \text { a } 8 \text { horas semanais - } 37,1 \% \text { Acima de } 16 \text { horas semanais } \\
\qquad-22,9 \%\end{array}$ \\
\hline Carga horária institucional dedicada à modalidade presencial & Acima de 16 horas semanais: $37,1 \%$ \\
\hline Percepção real de trabalho & Entre 4 e 8 horas semanais: $40 \%$ \\
\hline Locais que desenvolvem suas atividades da EAD & Residências: $67,1 \%$ \\
\hline Alunos por professor em uma turma virtual & $\begin{array}{c}50 \text { até } 100 \text { alunos por turma: } 35,7 \% \\
100 \text { até } 150 \text { alunos: } 30 \%\end{array}$ \\
\hline Renda da atividade docente de forma geral & Acima de 8 salários-mínimos: 32,9\% \\
\hline Renda predominantemente advinda da EAD & Entre 25 a $50 \%$ do total da sua renda geral: $50 \%$ \\
\hline
\end{tabular}

Tabela 4 - Avaliação do professor sobre o trabalho desenvolvido em EAD

\begin{tabular}{lc}
\hline Variável & Professores da EAD \\
\hline Avaliação sobre o tipo de trabalho na EAD & $94,3 \%$ consideram necessário \\
$\begin{array}{l}\text { Avaliação sobre o efeito da prática do tipo EAD em sua atuação } \\
\text { docente }\end{array}$ & $92,9 \%$ apontam que a EAD contribui \\
$\begin{array}{l}\text { Importância do trabalho em relação aos instrumentos } \\
\text { tecnológicos e virtuais da EAD }\end{array}$ & $71,4 \%$ consideram importante e insubstituível \\
Motivação para o trabalho em EAD & $65,7 \%$ consideram o tipo de atividade pedagógica motivadora \\
Preparação oferecida pela IES para atuar na EAD & $65,7 \%$ consideram que contribui \\
Contribuição dos colegas de profissão para a prática em EAD & $55,7 \%$ consideram que contribui \\
\hline
\end{tabular}

Psicol. Argum. 2014 jul./set., 32(78), 117-125 
Tabela 5 - Dados de caracterização dos grupos a partir das variáveis de maior valoração

\begin{tabular}{lcc}
\hline $\begin{array}{l}\text { Caracterização dos grupos considerando } \\
\text { as variáveis de maior valoração }\end{array}$ & $\begin{array}{c}\text { Grupo T } \\
\text { (representam 60,3\%) }\end{array}$ & $\begin{array}{c}\text { Grupo P } \\
\text { (representam 39,7\%) }\end{array}$ \\
\hline 1. Função & $90,2 \%$ tutores a distância & 100\% professor regente \\
2. Titulação & $43,9 \%$ mestres & $70,4 \%$ doutores \\
3. Renda & De 3 a 5 salários-mínimos & Acima de 8 salários-mínimos \\
4. Atividades desenvolvidas na EAD & Tutoria & Tarefas de concepção e tutoria \\
5. Forma de ingresso na EAD & 50\% por seleção & $71,4 \%$ por convite; designação funcional \\
6. Instituição de vinculação & $50 \%$ Privada e 50\% Pública & 100\% Pública \\
\hline
\end{tabular}

Tendo em vista a existência de dois grupos distintos na amostra é importante realizar uma breve caracterização descritiva de cada um deles. O Grupo T, isto é, o grupo dos tutores a distância, que corresponde a $60,3 \%$ da amostra, de formal geral, caracteriza-se por uma amostra tipicamente feminina $(73,7 \%)$. $50 \%$ são casadas/união estável, 57,9\% atuam na EAD entre 6 meses e 2 anos, e geralmente ingressaram por seleção $(55,3 \%)$, e $97,4 \%$ lecionam em cursos de graduação. 42,1\% possuem entre 1 a 5 anos de vínculo empregatício na sua atual instituição de trabalho; dividem-se proporcionalmente entre instituições públicas e privadas $(47,4 \%$ são de IES pública e $47,4 \%$ de IES privada). $36,8 \%$ trabalham mais de 16 horas semanais nas atividades de EAD, e 42,1\% são responsáveis por turmas de 100 a 150 alunos, desenvolvendo suas atividades de EAD, geralmente, em suas residências (84,2\%). 42,1\% ganham entre 1 a 3 salários-mínimos, sendo a contribuição da EAD na renda em torno de 25 a $50 \%$.

Quanto às atividades, 97,4\% realizam somente acompanhamento aos alunos e a grande maioria $(81,6 \%)$ não realiza tarefas de concepção e realização de cursos, bem como não realizam planejamento e organização de materiais, e administração acadêmica. $76,3 \%$ consideram a prática da EAD importante; $60,5 \%$ sentem-se motivados; $71,1 \%$ sentem o apoio da IES na atividade; $63,2 \%$ sentem apoio dos colegas de profissão para sua atuação nessa modalidade; por fim, 94,7\% consideram que a EAD contribui para sua atuação como docente de modo geral.

Em relação à diferenciação por subgrupos, foram destacadas variáveis de descrição e diferenciação do perfil socioprofissional, a saber: para o grupo de tutores que ensinam no âmbito privado, 66,7\% são casadas/união estável, sendo $61,1 \%$ especialistas; $66,7 \%$ atuavam na EAD entre 6 meses e 2 anos, e
$61,1 \%$ na modalidade presencial há mais de 6 anos. $44,4 \%$ ingressaram na EAD através de convite, e $38,9 \%$ dedicavam-se às atividades da EAD de 8 a 12 horas semanais; já no ensino presencial $50 \%$ trabalham mais de 16 horas semanais. Ganhavam entre 5 e 8 salários-mínimos (55,6\%), e 50\% apontaram que a contribuição da EAD na renda mensal é em torno de 25 a $50 \%$ do valor total.

No grupo dos tutores do âmbito público caracterizavam-se por $72,2 \%$ de mulheres, sendo $55,6 \%$ delas solteiras, com titulação dividida entre mestras (50\%) e graduadas $(44,4 \%) .55,6 \%$ atuavam na EAD entre 6 meses e 2 anos; na modalidade presencial há uma divisão entre tutores que estão trabalhando há menos de 6 meses (38,9\%), seguido daqueles que estão entre 2 e 4 anos (22,2\%). 83,3\% ingressaram na EAD por meio de seleção, e 55,6\% dedicavam-se a uma carga horária de mais de 16 horas semanais para as atividades da EAD; na presencial $44,4 \%$ trabalhavam menos de 4 horas. Ganhavam entre $1 \mathrm{e}$ 3 salários-mínimos (66,7\%), obtendo da EAD uma contribuição de 50 a $75 \%$ da renda total $(50 \%$ dos docentes).

Sobre a caracterização do Grupo P, dos professores regentes, as variáveis em destaque apontam um perfil tipicamente de homens $(58,1 \%)$, e exclusivamente de instituição pública (90,3\%). São, na maioria, doutores $(64,5 \%)$, e $38,7 \%$ atuavam na EAD entre 6 meses e 2 anos; $54,8 \%$ deles estão atuando há mais de 6 anos no ensino presencial. Em termos de carga horária de trabalho na EAD, $58,1 \%$ dedicam de 4 a 8 horas semanais, enquanto que, na presencial, apenas $32,3 \%$ trabalham mais de 16 horas. $71 \%$ ganhavam acima de 8 salários-mínimos, sendo de 25 a $50 \%$ da renda total advindas da atividade de EAD (58,1\% dos docentes). $74,2 \%$ realizavam atividades de concepção e realização de cursos, e 54,8\% desenvolviam atividades de tutoria. 


\section{Discussão}

0 mapeamento do perfil dos professores que atuam em EAD apontou a existência de dois grupos na amostra, representados pelos professores regentes e tutores. A existência dos grupos assinalou também a segmentação de dois modelos de EAD. No modelo cuja existência da figura docente é representada por três funções (professor regente, tutor presencial e a distância), a atividade do professor é compartilhada, sendo atividade do professor regente a sincronização (harmonização) das atividades na turma virtual. No modelo em que a figura docente é centrada no tutor, todas as atividades relativas à docência centralizavam-se nessa figura.

Observou-se que o Grupo T é composto por tutores de IES diferentes, e com atribuições de função também distintas. Nas visitas de aproximação com o campo, e no acesso ao manual descritivo das funções dos tutores de cada instituição, percebe-se uma diferenciação entre os tutores a distância do âmbito público e aqueles que trabalham na IES privada. Na IES pública existem, como foi definido anteriormente, em termos de atividades prescritas, três figuras no processo de ensino-aprendizagem: o professor regente, os tutores presenciais e a distância. Logo, há uma divisão de tarefas de acordo com as atividades executadas. Na IES privada há apenas a figura do tutor a distância para desempenhar o papel docente nesse cenário de EAD.

Em termos comparativos, os dois grupos da pesquisa ( $\mathrm{T}$ e P) apresentam características de perfil distintas, não somente em termos de função, mas de característica de titulação; por exemplo, o Grupo $\mathrm{P}$ é formado praticamente por doutores, que recebem mais de 8 salários-mínimos e realizam tarefas tanto de tutoria como de concepção, para terem uma visão mais global do processo de ensino-aprendizagem, tanto no que concerne à execução, quanto no que se refere à elaboração e reflexão desses processos.

No Grupo T, composto pela figura do tutor, um aspecto a ser destacado é que, em termos de atividades desenvolvidas, somente aquelas relacionadas ao acompanhamento do aluno foram mencionadas. Característica que revela, até certo ponto, formatos de EAD distintos. Pois nesse grupo há tanto professores-tutores que assumem a figura da docência de modo compartilhado, aqueles vinculados à IES pública, quanto aqueles que têm a figura de docência centrada apenas no tutor. Nesse aspecto, em que medida a figura do professor coletivo, conceito já elucidado por Belloni (2001), afasta-se em um formato de EAD centralizado na figura do tutor?

Alertas podem ser lançados quando são concebidos formatos de EAD cuja tendência à intensificação e individualização do trabalho é característica comumente presente, o que corrobora os atuaismodos detrabalho docontexto contemporâneo. A importância das trocas realizadas pelos coletivos de trabalho nos cenários de mudança das atividades de trabalho é essencial ao desenvolvimento do ofício.

Os modelos massivos e instrumentais de EAD tendem a centralizar a figura do docente em único ator - o tutor. No entanto, não é somente pela não coletivização do trabalho docente, mas pelo próprio isolamento que o modelo coloca, dirimindo os espaços de diálogo, e, por conseguinte, a ação de coletivos de trabalho. Assim esses formatos de EAD diminuem o raio de ação dos trabalhadores.

No que se refere às relações precarizadas de trabalho, a intensificação do trabalho do professor (rever proporção de alunos por professor em cada grupo da pesquisa) são distintas, principalmente quando se destaca seus vínculos institucionais. Sobre o desenvolvimento das atividades do professor na EAD, há uma segmentação clara entre os grupos, os tutores (independentes das IES) não realizam tarefas de concepção dos cursos, por exemplo, apontando desse modo que o alargamento do leque de atividades dos docentes não necessariamente está atrelado a uma concepção mais ampliada de educação.

Todos os professores da EAD geralmente lecionaram a disciplina em cursos presenciais, e apesar de apontarem convergências quanto à importância insubstituível do professor nesse espaço, conforme se observa nos percentuais dos grupos estudados, suas atividades, em termos de enfoque, são diferentes, o que traduz, mesmo que sutilmente, formas de concepção distintas de EAD. 0 fato de lecionarem no presencial, conforme aponta os estudiosos em EAD (Belloni, 2001; Lapa \& Pretto, 2010; Litwin, 2001; Peters, 2006, 2004) não garante boa adaptação ao espaço da modalidade a distância, pois a transposição de uma modalidade para outra é uma das dificuldades frequentemente encontradas.

0 alargamento das atividades não pode ser apenas no âmbito das competências técnicas, de como lidar com as NTICs, fato de extrema importância para a concretização da EAD. Mas ampliam-se as

Psicol. Argum. 2014 jul./set., 32(78), 117-125 
competências pedagógicas, isto é, referem-se aos modos como o processo de ensino-aprendizagem é contemplado, aos papéis dos atores desse processo, e aos ideais de educação que postulam em seus espaços de ensino.

Por fim, aponta-se que o mapeamento socioprofissional possibilitou o conhecimento das principais características sociodemográficas e de perfil profissional do grupo de professores da EAD de duas universidades do RN. O perfil descritivo demarcou a existência de dois grupos na amostra que são representativos para a compreensão das especificidades dos modelos de EAD propostos no cenário local. Essa atividade de mapeamento não tinha sido até então sistematizada em um estudo descritivo. Houve também o intuito de se articular as informações do mapeamento com outra etapa de análise qualitativa (aqui não enfocada), a qual foi norteada pelo critério de escolha de representatividade dos grupos encontrados nas análises quantitativas inferenciais (clusterização). Nesse sentido, em termos de objetivos, as etapas se propuseram a fins diferentes, e contemplavam dimensões de análises distintas e importantes para a compreensão do cenário estudado.

\section{Considerações finais}

A pesquisa contemplou, mesmo que de forma incipiente, um campo de discussão extremamente importante para o cenário educacional: a presença premente da EAD como modalidade de educação na contemporaneidade. As mudanças não são apenas da ordem de tempo e espaço, notadamente, no que se refere à presença de uma modalidade de educação que atende aos preceitos da globalização e ao cenário de uma sociedade digital.

Há reflexos nos modelos e concepções dos processos de ensino-aprendizagem e, com isso, os autores envolvidos no processo têm seus espaços de atuação reconfigurados. Tanto o aluno quanto o professor são tomados a ocupar papéis em certa medida distintos dos que habitualmente estavam "aculturados" no ensino presencial. Essa reconfiguração também reflete nas IES que, imbuídas da missão de ofertar acesso a uma educação de qualidade, enfrenta problemas não apenas na transposição de uma modalidade para outra, mas se amplia aos propósitos da EAD nesse espaço de construção do saber.
No estudo, o enfoque foi dado ao professor no cenário da $\mathrm{EAD}$. Ao serem assinalados os desafios que esse profissional encontra, é necessário repensar a diversificação do seu leque de atividades, as dificuldades de transposição de uma modalidade para outra, e as funções de seu trabalho que se alargaram. No entanto, as dificuldades não são inerentes apenas à competência em lidar com as ferramentas de interatividade virtual (competência técnica), mas os profissionais são convidados a refletir sobre suas próprias concepções pedagógicas de ensino-aprendizagem (competências pedagógicas) que circundam o modelo de educação, e fundamentalmente a refletir sobre sua função na relação professor/aluno, que não se estabelece mais da mesma maneira que no modelo presencial.

0 mapeamento, desenvolvido nas duas universidades de Natal sobre o perfil "de quem é" esse professor que ensina a distância, concedeu dados gerais de caracterização do grupo de profissionais estudado. Apontou a existência de dois grupos distintos na amostra estudada, o que possibilitou a compreensão da relação entre os perfis de professores da EAD e os modelos de EAD adotados pelas IES.

Os professores que tiveram contato com modelos de ensino a distância distintos, vivenciam diferenças na forma de conceber o papel docente. Notadamente, a problemática surge quando a modalidade presencial é tida como um guia norteador a suas ações docentes de modo geral, referindo-se tanto ao professor quanto ao aluno. Nesse sentido, alerta-se mais uma vez para necessidade de estudos que enfoquem os papéis do professor, do aluno e das demais instâncias envolvidas na EAD, já que esse tipo de educação requer uma dinâmica diferente do modelo tradicional (presencial), conforme apontam estudiosos da EAD (Belloni, 2001; Litwin, 2001; Peters, 2004, 2006).

0 caráter recente da EAD no cenário regional convoca as IES a pensar meios de os professores vivenciarem outras maneiras dos processos de ensino-aprendizagem, condizentes com as concepções de educação postuladas em seus espaços pedagógicos e embutidas em seus processos de formação. No entanto, esse movimento nem sempre é factível de realização, há entraves de cunho organizacional, político e ideológico para a concretização. A instrumentalidade da educação é tendenciosa, e o alerta para esses modelos de EAD instrucionais é discrepante em relação ao alargamento das fortes demandas de expansão que atravessam os cursos a distância. 


\section{Referências}

Abreu-Tardelli, L. S. (2006). Trabalhoprofessor@chateducacional.com.br. Aportes para compreender o trabaIho do professor iniciante em EAD. Tese de doutorado, Pontifícia Universidade Católica de São Paulo, São Paulo.

Almeida, M. E. B. (2005). Desafios e possibilidades da atuação docente on-line. Revista Puc Viva, (24). Recuperado em 10 set. 2011, de http://www.apropucsp.org.br.

Alves, L. R. G., \& Nova, C. C. (2002). Tempo, espaço e sujeitos da educação a distância. In Internet e educação a distância. (pp. 41-55). Salvador : Edufba.

Barreto, R. G. (2004). Tecnologia e educação: trabalho e formação docente. Educação \& Sociedade, Campinas, 25(89), 1181-1201.

Belloni, M. L. (2001). Educação a distância. 2. ed. Campinas, São Paulo: Autores Associados.

Gonzalez, M. (2005). Fundamentos da tutoria em educação a distância. São Paulo: Editora Avercamp.

Lapa, A., \& Pretto, N. D. L. (2010). Educação a distancia e precarização do trabalho. Em Aberto, Brasília, 23(84), 79-97.

Litwin, E. (2001). Das tradições à virtualidade. In E. Litwin (Org.). Educação a distância. Temas para o debate de uma nova agenda educativa. (pp. 13-22). Porto Alegre: Artmed.
Brasil (2010). Ministério da Educação. Sistema de consulta de instituições credenciadas para educação a distância (SIEAD). Recuperado em 20 de setembro de 2010, de http://siead.mec.gov.br/novosiead/web/ site/\#tab=1.

Moraes, R. A. (2003). Educação a distância: aspectos histórico-filosóficos. In L. M. R. Fiorentini, \& R. A. Moraes (Orgs.). Linguagens e interatividade na educação a distância. (pp. 111-132). Rio de Janeiro: DP\&A.

Oliveira, E. M. (2005). Educação a distância: a velha e a nova escola. Revista Puc Viva, (24). Recuperado em 10 set. 2011, de http://www.apropucsp.org.br

Peters, O. (2004). A educação a distância em transição. Tendências e desafios. (L. F. Mendes, Trad.). São Leopoldo: Unisinos.

Peters, 0. (2006). Didática de ensino a distância. Experiência e estágio da discussão numa visão internacional. (J. Kayser, Trad.). São Leopoldo: Unisinos.

Sarmet, M. M., \& Abrahao, J. I. (2007). O tutor em educação a distância: análise ergonômica das interfaces mediadoras. Educação em Revista, 46, 109-141.

Torres, C. C. (2007). A educação a distância e o papel do tutor: contribuições da ergonomia. Tese de Doutorado, Universidade de Brasília, Brasília.

Psicol. Argum. 2014 jul./set., 32(78), 117-125 